\title{
The Value of (Research on) Animals in Children's Lives
}

\author{
Commentary on Mueller \\ Rachel L. Severson \\ University of British Columbia, Vancouver, B.C., Canada
}

\author{
Key Words \\ Animals · Children · Human-animal interaction · Positive youth development
}

If numbers are any indication, then it appears animals play an important part in people's lives. Roughly three-quarters of families with children (and two-thirds of Americans in general) have a pet in their homes [American Veterinary Medical Association, 2007]. The hallowed place of animals is not restricted to modern times. Rather, evidence abounds of the unique place animals - particularly domesticated animals - have held over the millennia, perhaps most canonically in the form of selective breeding of species such as dogs for specific purposes [Shepard, 1997]. While we cannot say precisely at what point domesticated animals stepped over the threshold from instrumental use to social companions (or perhaps these roles have largely co-existed), we can say that many animals are considered to be important members of their human families with many, if not most, of the accompanying treatment and privileges.

What role then do animals play in humans' lives? A cursory response might include something of the following: Animals provide companionship, entertainment, and an opportunity for children to learn responsibility. Yet, as the research on human-animal interaction (HAI) suggests, animals do more than that. The mere presence of companion animals reduces people's blood pressure and heart rate [for a review, see Wells, 2009]. These benefits are increased with physical contact, such as petting, with even greater physiological benefits in people [Shiloh, Sorek, \& Terkel, 2003] and a reduction in animals' heart rates as well [McGreevy, Righetti, \& Thomson, 2005]. Companion animals, particularly dogs, also function as social facilitators, increasing social interactions among people in public settings [Wells, 2004] and in long-term care facilities [Bernstein, Friedmann, \& Malaspina, 2000].

These findings have led to the therapeutic use of animals in hospitals, nursing homes, prisons, and inspired further research on the range of therapeutic benefits of

\begin{tabular}{ll}
\hline KARGER & ○ 2014 S. Karger AG, Basel \\
E-Mail karger@karger.com & 0018-716X/14/0571-0026\$39.50/0 \\
www.karger.com/hde
\end{tabular}

Rachel L. Severson

Department of Psychology

University of British Columbia

2136 West Mall, Vancouver, B.C. V6T 1 Z4 (Canada)

E-Mail rachel@psych.ubc.ca 
animals. Most notably, animal-assisted intervention research has provided evidence of positive outcomes for children with autism spectrum disorder (ASD), conduct disorder, and attention-deficit hyperactivity disorder, as well as for children in medical settings [for reviews, see Nimer \& Lundahl, 2007; O'Haire, 2013]. Meta-analyses of animal-assisted intervention research show a range of benefits, including increased social interaction and communication, as well as reduced stress (cortisol response), severity of ASD symptoms, and aggressive behavior [Nimer \& Lundahl, 2007; O'Haire, 2013]. In an intriguing twist on animal therapy, therapeutic use of animal robots has shown a similar pattern of results [Diehl, Schmitt, Villano, \& Crowell, 2012]. For example, children with ASD spoke more with an adult researcher when interacting with an animal-like robot compared to interacting with a non-robotic mechanical toy [Stanton, Kahn, Severson, Ruckert, \& Gill, 2008] or with a human partner or computer [Kim et al., 2012].

The existing HAI research is promising and provocative. On the one hand it provides evidence of the value of animals in therapeutic contexts and, on the other hand, raises questions of why and how animals garner these benefits. At the same time, HAI research has serious limitations. Mueller [this issue] provides a clear-headed critique of the field and, importantly, offers insightful suggestions for moving the HAI field forward.

Mueller points out that much of the HAI research has serious methodological limitations that call into question the robustness and generalizability of these findings. Central to these limitations are small sample sizes, lack of replication, and correlational, as opposed to experimental, research designs. In concert with other HAI researchers [e.g., Esposito, McCune, Griffin, \& Maholmes, 2011], Mueller calls for more empirically rigorous, theoretically-grounded research. To provide some perspective on this issue, it is often the case that new areas of investigation undergo transitions in the rigor of their methodologies, moving from description to explanation and prediction. In my view, the field of HAI research is undergoing such a methodological development, motivated by scholars such as Mueller to drive the field forward.

Towards a solution for these above limitations, Mueller suggests a relational developmental systems approach as a theoretical framework for conceptualizing, organizing, and investigating HAI research questions. Three benefits can be distilled from using such an approach. First, as an ecological systems theory, Mueller suggests this approach can capture the complex components of HAI, such as the structure of the interaction (e.g., companion vs. competition), type of animal, and the quality and duration of the interaction. Second, it provides a developmental approach that would move beyond a "snapshot" of short-term effects to consider instead the developmental trajectories and outcomes. Third, an interactional approach would provide a structure for moving beyond an "animal as treatment" modality to take into account the reciprocal aspects of interactions between animals and people. The relational aspects of HAI may mimic in some ways, in form or consequence, human-human interaction. This is an intriguing idea to which I will return below.

Arguably, the most salient element of the existing HAI research is the focus on therapeutic benefits of animals, primarily for clinical populations. Mueller argues for increasing the scope of HAI research to move beyond the treatment model to include a focus on "promoting pathways to positive development." To elaborate on this idea, Benson, Scales, Hamilton, and Sesma [2006] distinguish positive youth development 
from traditional child development approaches, arguing that, “... understandings of child and adolescent development have been so dominated by the exploration and remediation of pathology and deficit that we have an incomplete - if not distorted view of how organisms develop" (p. 895). Thus, the overarching focus of positive youth development is on the promotion of competencies and attributes necessary for well-being, thriving, and flourishing, rather than a primary focus on reduction of maladaptive behaviors. The field of positive youth development is based in relational developmental systems theory - the individual is situated within a community of "relationships, contexts, and ecologies" [Benson et al., 2006, p. 896], which provide both the container and fodder for development. Traditionally conceived, the constituents of this community are people (e.g., family, peers, neighbors, school, congregations, workplace, etc.). The thrust of Mueller's argument is that animals are also an important constituent of children's lives, influencing their development in positive ways.

Does this mean pets have joined the ranks of parents and peers in terms of their importance in children's lives? Some evidence suggests children seem to think so. Mueller, citing work by Kosonen [1996], notes that for nearly half of children (9-12 years), pets provide a more important relationship than friends, grandfathers, and teachers. Researchers seem to think so, too. According to Esposito et al. [2011], "major developmental changes in how children interact with pets are generally parallel to the developmental changes in interaction patterns that children have with familiar humans, including parents, siblings, and peers" (pp. 205-206). Drawing on this comparison, a potentially fruitful approach for future HAI research would be to investigate the influence of animals on children's development using analogous questions and methods as those used to study the influence of parents and peers. Research on human-computer interaction has been successful using a comparable move, replicating with "social" computers classic social psychology studies [e.g., Nass \& Moon, 2000].

With respect to positive youth development, Mueller provides suggestions for a range of cognitive, social, moral, and physical outcomes that may follow from HAI. I would like to highlight some existing work to shed light on how an HAI might contribute to basic research questions, in addition to more applied questions relevant to positive youth development. One debate in the field focuses on the role of experience with animals in the tendency to reason anthropocentrically about biological kinds. Research suggests that anthropocentric thinking is a consequence of relatively little direct experience with animals [Hatano \& Inagaki, 1994; Inagaki, 1990; for a review, see Waxman \& Medin, 2007]. However, recent research suggests a different trajectory. That is, children appear to learn to think anthropocentrically [Herrmann, Waxman, \& Medin, 2010]. Thus, anthropocentrism may be cultural product, rather than a default conceptualization that is overwritten by experience. A second, and final, example aligns with an outcome identified by Mueller; that is, moral development. Empirical work on children's environmental moral reasoning found that children living in a farm environment think about nature (including animals) as having intrinsic moral value [Severson \& Kahn, 2010]. These findings contradicted previous work that found very little "biocentric" moral reasoning in urban children [Kahn \& Friedman, 1995; Kahn, Severson, \& Ruckert, 2009]. While the disparity may reflect the methodological differences, the difference might also be explained by the relative differences in experiences with nature and animals between farm and urban children. These alternative views and contradictory findings illustrate the need for additional 
research on the role of experience, particularly with animals, in the formation of biological knowledge and environmental moral reasoning.

The field of HAI is on the cusp of making important and necessary advances. Mueller provides a comprehensive structure for investigating the role of HAI. This approach is theoretically grounded, thereby providing a robust framework for capturing the complexities and outcomes of HAI, with a primary focus on how HAI can positively support youth development. The field will benefit tremendously by heeding Mueller's astute suggestions.

\section{References}

American Veterinary Medical Association (2007). US pet ownership and demographics sourcebook. Schaumburg, IL: American Veterinary Medical Association.

Benson, P.L., Scales, P.C., Hamilton, S.F., \& Sesma, A., Jr. (2006). Positive youth development: Theory, research, and applications. In R.M. Lerner (Vol. Ed.), Handbook of child psychology: Vol. 1. Theoretical models of human development (6th ed., pp. 894-941). Hoboken, NJ: Wiley.

Bernstein, P.L., Friedmann, E., \& Malaspina, A. (2000). Animal-assisted therapy enhances resident social interaction and initiation in long-term care facilities. Anthrozoös, 13, 213-224.

Diehl, J.J., Schmitt, L.M., Villano, M., \& Crowell, C.R. (2012). The clinical use of robots for individuals with autism spectrum disorders: A critical review. Research in Autism Spectrum Disorders, 6, 249262.

Esposito, L., McCune, S., Griffin, J.A., \& Maholmes, V. (2011). Directions in human-animal interaction research: Child development, health, and therapeutic interventions. Child Development Perspectives, $5,205-211$.

Hatano, G., \& Inagaki, K. (1994). Young children's naïve theory of biology. Cognition, 50, 171-188.

Herrmann, P., Waxman, S.R., \& Medin, D.L. (2010). Anthropocentrism is not the first step in children's reasoning about the natural world. Proceedings of the National Academy of Sciences, 107, 9979-9984.

Inagaki, K. (1990). The effects of raising animals on children's biological knowledge. British Journal of Developmental Psychology, 8, 119-129.

Kahn, P.H., Jr., \& Friedman, B. (1995). Environmental views and values of children in an inner-city Black community. Child Development, 66, 1403-1417.

Kahn, P.H., Jr., Severson, R.L., \& Ruckert, J.H. (2009). The human relation with nature and technological nature. Current Directions in Psychological Science, 18, 37-42.

Kim, E.S., Berkovits, L.D., Bernier, E.P., Leyzberg, D., Shic, F., Paul, R., \& Scassellati, B. (2012). Social robots as embedded reinforcers of social behavior in children with autism. Journal of Autism and Developmental Disorders, 43, 1038-1049.

Kosonen, M. (1996). Siblings as providers of support and care during middle childhood: Children's perceptions. Children \& Society, 10, 267-279.

McGreevy, P.D., Righetti, J., \& Thomson, P. (2005). The reinforcing value of physical contact on the effect on canine heart rate of grooming in different anatomical areas. Anthrozoös, 18, 236-244.

Nass, C., \& Moon, Y. (2000). Machines and mindlessness: Social responses to computers. Journal of Social Issues, 56, 81-103.

Nimer, J., \& Lundahl, B. (2007). Animal-assisted therapy: A meta-analysis. Anthrozoös, 20, 225-238.

O'Haire, M.E. (2013). Animal-assisted intervention for autism spectrum disorder: A systematic literature review. Journal of Autism and Developmental Disorders, 43, 1606-1622.

-Severson, R.L., \& Kahn, P.H., Jr. (2010). In the orchard: Farm worker children's moral and environmental reasoning. Journal of Applied Developmental Psychology, 31, 249-256.

Shepard, P. (1997). The others: How animals make us human. Washington, D.C.: Island Press.

Shiloh, S., Sorek, G., \& Terkel, J. (2003). Reduction of state-anxiety by petting animals in a controlled laboratory experiment. Anxiety, Stress, and Coping, 16, 387-395.

Stanton, C.M., Kahn, P.H., Jr., Severson, R.L., Ruckert, J.H., \& Gill, B.T. (2008). Robotic animals might aid in the social development of children with autism. Proceedings of the 3rd ACM/IEEE International Conference on Human-Robot Interaction (pp. 271-280). New York, NY: ACM Press.

Waxman, S., \& Medin, D. (2007). Experience and cultural models matter: Placing firm limits on childhood anthropocentrism. Human Development, 50, 23-30.

Wells, D.L. (2004). The facilitation of social interactions by domestic dogs. Anthrozoös, 17, 340-352.

Wells, D.L. (2009). The effects of animals on human health and well-being. Journal of Social Issues, 65, 523-543. 